\title{
ACCESS AND CONNECTION VIA TECH DATA AS AN ENABLER AF A THIN OR NON- EXISTENT MARKET
}

\author{
Bathabile S C Amirchand
}

Founder Gropeedy App, South Africa

\begin{abstract}
This study provides a prototype of Real estate listing mobile application that has the capability to organize, store, maintain and search data from a Mobile Device such as android or iOS. This application helps the household owners to list their properties without any cost. This system comprises of a mobile app, Central Database, Satellite database and offline database system. It consists of software that combines one or more servers to the computer as well as to the Mobile user, making it a Mobile app and A Web Browser. Apple Mac OSX working framework can also be utilized to make this framework. This Suite of apparatuses involves graphical UI (GUI) based applications, command- line instruments, and documentation to help in the product advancement process. This will pave a way to formalize the much-neglected Former Homelands (Village Sector) and facilitate the development of an inclusive real estate Evaluation Data, thus, enabling access to areas where there has been no base price until now.
\end{abstract}

\section{KEY WORDS}

Data, Application, Real-estate, Technology, Connection and System

\section{INTRODUCTION}

Global development of Information Technology has substantially changed the real-estate industry massively. The South African economy has been positioned as an attractive emerging market in the African Region. [1] Despite that, the residential Sector here appears to be least feasible to foreign and local investors due to un-availability of Complete Household listing information. [2] As the South African economy has lagged behind many developing countries, these mega advancements in technology can benefit the economy and expand businesses. The current Realestate Industry in South Africa provides limited resources to lawn owners who are not tech savvy. Many Households are not listed and it is hard to find data related to real estate evaluations. [3] This causes hindrance for the investors who want land or farms for their businesses in places where there has been no base price until now. South African Listed property sector has performed significantly but the majority of landowners keep them unlisted due to High Self-Listing Fees and Agent fees. In addition, there is little trend about self-listing most home owners still rely on agents to list on their behalf. This study involves the development of a Mobile Application system for free - Real Estate Formal and Former Homelands (also referred to as Villages) Residential / Settlement listing. 


\section{RELATED WORK}

One of the previous works involving the modelling and estimation of a smart information based real-estate online platform is (Qing $\mathrm{Li}$, Shimin $\mathrm{Hu}$. (2016) Modeling and simulating a smart information-based real estate online platform) based on their article. This study applies $\mathrm{O} 2 \mathrm{O}$ model of business for property purchases. Information- based Real estate platform I-rep uses internet and mobile apps to connect with the customers via agents. This app engages customers along with their agents by resource sharing using $\mathrm{O} 2 \mathrm{O}$ model. This model allows extensive scope of items to potential purchasers, prompting better coordination among requests and supplies. IREP is displayed utilizing BPR demonstrating device for outlining its model structure and the qualities that stream inside the federation framework among the individuals or agents included.[4] Another study explains the use of Cloud technology software TeamProQ.de that supports builders, property developers and mangers in maintenance of property portfolios of various real estates. Furthermore, it is also advantageous to the individuals to reserve, buy, sell, and rent real estates in real time. [5]Another study uses Automated Valuation model for insufficient real estate market data by applying Fuzzy and rough set theory, markets that exhibit lack of information or due to little data available for analysis and this method proved fruitful. It can be utilized in the valuation of business properties, in the mass examination process, in the valuation of land portfolios and in supporting property valuation for home-loan loaning purposes, just to reconsider properties, or for powerful simplified valuation plans.[6]

\section{Proposed DESIGN}

This mobile application provides an interactive scenario where real estate portfolio generation is free for areas where high agent fee and lack of knowledge about self-listing has left most of the real estate unlisted. The market and service providers have listed less than $45 \%$ of household real estate preventing them from possible market expansion. This is not only limited to Household listing but also includes Listing of Informal settlements either on lease from Ingonyama Trust Board with a letter of settlement from induna or nothing at all. This Real-estate Listing Application includes a central office connected to Satellite office and to one or more mobile devices via internet. Central office consists of a database where the mobile device users can store and maintain real estate data through internet without any cost.Internal Users/Moderators are connected to satellite office, containing a satellite database, which is further synchronized with Central database. Moderators can access, maintain and modify information related to property listing on both satellite and Central databases simultaneously through the same app or using web browsers. 


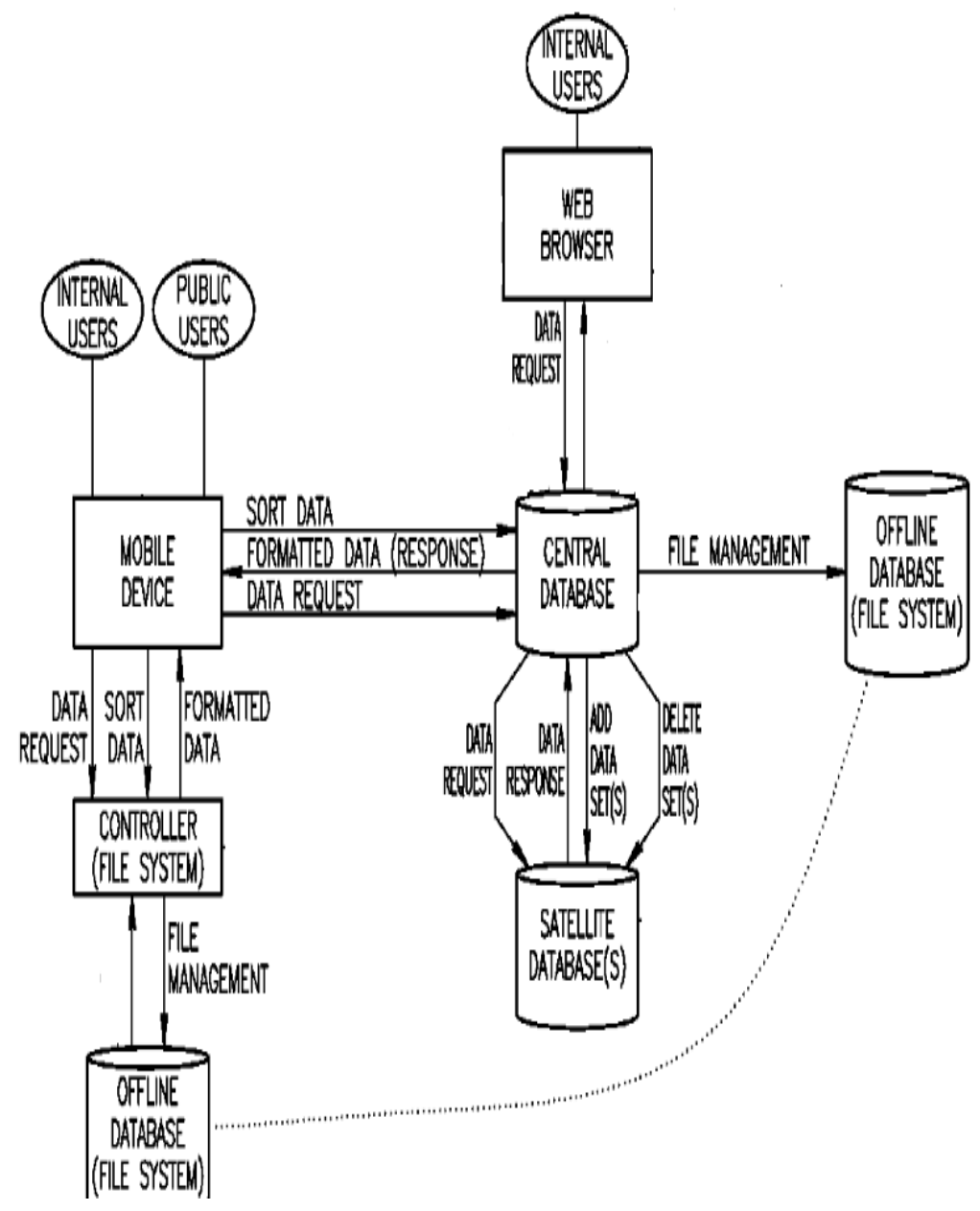

Fig. 1 Basic Working Process of This System.

Back end also contains a listing website where all the listed real estate is available and viewers can search and browse listed Portfolios. This Web browser is connected to Central Data Base that updates the website with the new entries listed. 


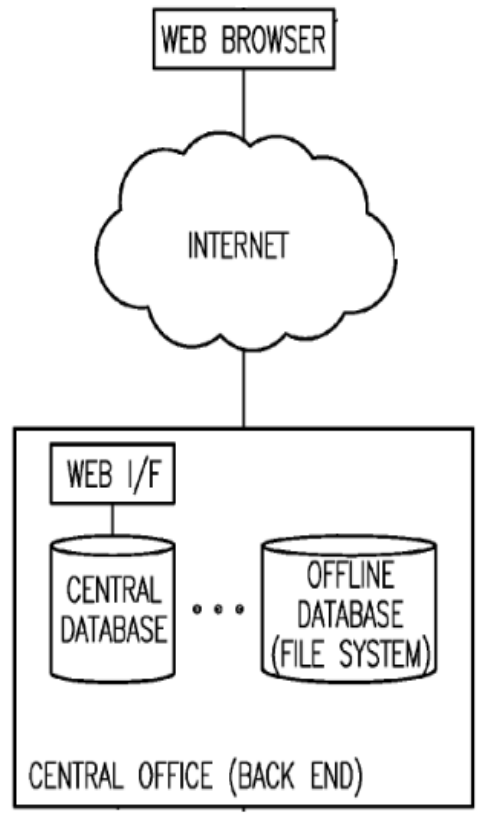

Fig. 2 Back End Browser

The potential investor can view Household portfolios through this Mobile application. Web User Interface (UI) adds and updates all the information regarding settlements i-e images, financial information, leasing agents and information regarding owners. This system gives internal users a free hand to login and sort data along with the management of portfolios and security data. Those who lists households are not aware thatthe new technology can even list their property by providing information through a phone call to internal users. Internal users can update the central database accordingly. Another feature of this system includes offline database. If the mobile device does not have internet connection or is unable to connect to central database, it can stillaccess data offline in the offline data base via controller (file system). The satellite data synchronizes with the controller and stores data offline, which then synchronizes itself automatically to the central Database.

The process of synchronization happens online and offline. The central base acts as a master database that stores, modifies, format and sorts data. Servers are divided into two distinct parts. The public version and the internal version. Public version consists of an operating system along with search task, display task, server interface task and user interface task. Additional tasks on public server can include Properties by Filters, Property area in Google Maps, View Property Information, View PDF Document on the property, and View Images on the property and Comparison of Portfolios between non-possessed Prospective properties. Internal versions comprise of an operating system, search task, user interface task, server interface task and display task. SSL protocol is used by the both the servers which includes additional tasks like Search Properties by Filters, Property area in Google Maps, View Property Information, View PDF Document on the property, View Images on the property, View Rent Roll data and Comparison of Portfolios between non-claimed Prospective properties. 


\section{Operating SYSTEMS}

The server can allow operating systems such as Linux, Sun OS, and Windows. It runs several tasks including subsystems and databases that are not specifically limited to IIS, FTP and SQL etc. The interface can be executed on a portable SDK stage for versatile advancements, for example, iPad and Android, Internal usershave substantial access than open users as the previous are in charge of making changes to the substance of the focal database.

Apple Mac OSX working framework can also be utilized to make this framework. This Suite of apparatuses involves graphical UI (GUI) based applications, command- line instruments, and documentation to help in the product advancement process. The Xcode application gives a groundbreaking UI for making and overseeing Software Projects. Xcode can be utilized to arrange and alter source records, see documentation, manufacture the application, investigate the code, and improve application execution. Application can be formed utilizing surely understood Object Oriented Principles (OOP). The increased exchange of code overhead and article message passing is supported by the expanded modularization of functionality, communication through interfaces, data encapsulation and the use of poly morphism. The versatile systemprovides a central infrastructure that oversees and runs the application under contrasting devices such as Android and iOS.

\section{SEARCH ProcesS}

The search procedure in the application is used to look for property via a certain criterion explained below. The specific database search depends on whether the cell phone user have it connected to the internet or not. If the mobile is connected to the internet, then the user is able to get data from the central database, the information recovered from the central database is stored in a central server in the cloud. Hence users require internet connection in order to access data. On the other hand, if the user is not connected to the internet then the user can only access data that from the offline database which is a file system that is stored locally on the mobile. The data modelling process is the procedure where elements of the data are organized and standardized with regards to one another and to the properties of real-world entities. The recovered information is prepared and the asked question results are shown to the client, hence the search process is very simple and any learned person will be able to do it. A chart delineating the parts of a first Internal User segment of the property-listing framework is present in fig: 


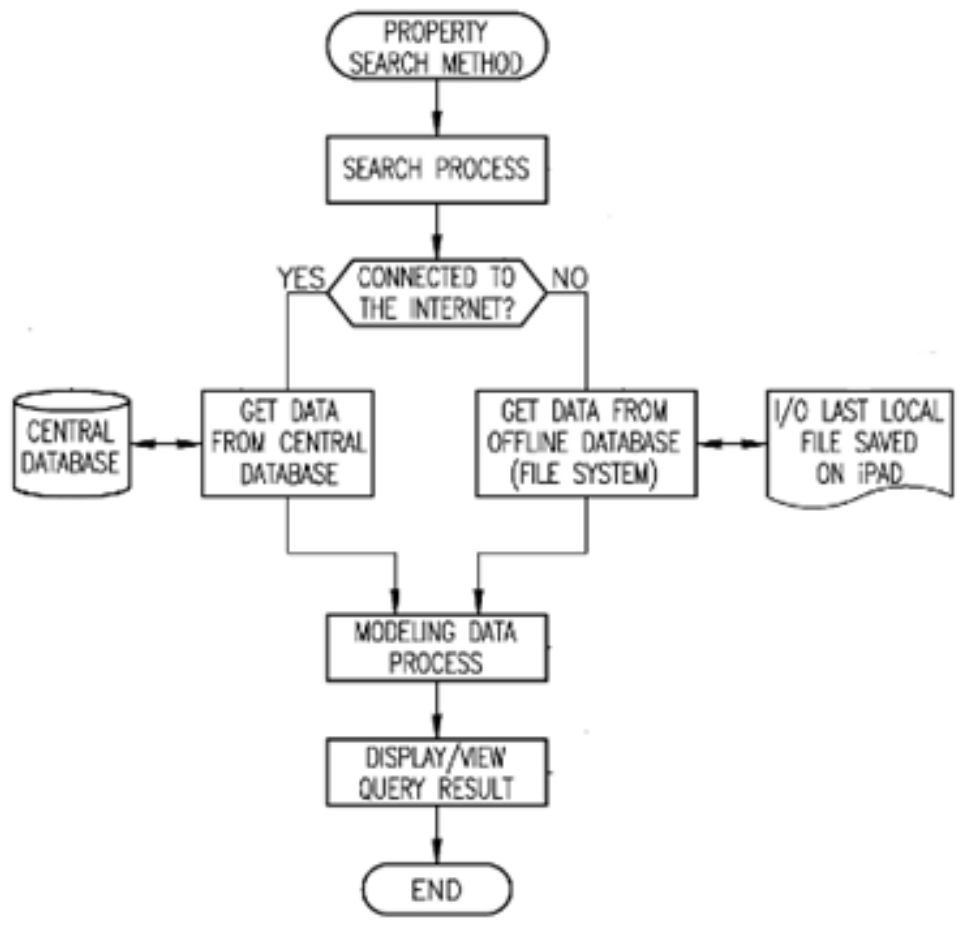

Fig. 3 Property Search Process

\section{Testing and Validation of The Prototype}

The Prototype mobile application was tested from May $1^{\text {st }} 2019$ to August $21^{\text {st }} 2019$ in real life conditions in a small Village outside Durban known as Engonyameni and it was able to execute its functionalities excellently. The Prototype was able to organize and store data for approximately 500 various properties in this location. This was done through the Beta released Application which allowed access to 1000 Users. For offsite support we had a central office in Pietermaritzburg which is connected to a Satellite office in the Engonyameni Village, which then connects to one or more mobile devices via internet. Central office consists of a database from the mobile devices where End-users are able to upload, store and maintain real estate data through the internet without any assistance or cost incurred. Internal Users/Moderators are connected to the satellite office, containing a satellite database, which is further synchronized with a Central database. Moderators could access, maintain and modify information related to property listings on the Central database to improve data quality and accuracy by utilizing the Prototype app's backend or the web browser.

The Prototype mobile application was able to assist home owners in Self-listing and managing their Real Estate listing from start to finish. The Central office, with the help of the Satellite office in Engonyameni Village, assisted in listing and providing cost free telephonic tech support to villagers that are not Tech savvy. The Data collected will enable greater access to the Village/Informal real estate market of the area. We anticipate most investor interest to come from the nearby Durban, as has been the case with the current Beta Testers from same. With the availability of correct Evaluation data of the unlisted households/land it became apparent that the Engonyameni Village has much value to offer at affordable rates. This makes Engonyameni a 
viable choice for an investor looking for an affordable alternative. The Application managed remove some Inhibitions to the private listing trend such as high listing fees and high Agent fees and this improved the trend in the area. In relation to real estate evaluation, the mobiles feed the data onto the Central Database, after which, Moderators could Access the area's base price for the first time. The Prototype was able to List and organize Data from various types of properties including Former Homelands (Villages) and Informal settlements. The Prototype was able to collect Data from not only properties with title deeds (these are in the neighboring Luganda location), but also properties on lease from the Ingonyama Trust Board.

\section{CONCLUSION AND Future WORK}

Real estate is considered as building block of any economy. Any opportunity that comes in the way of expanding must be availed to achieve the required growth targets. This prototype of the Mobile Application successfully solved the problem of un-listed households in the test Village (Engonyameni) and increased tech engagement as the prototype has explanations in isiZulu, an indigenous language in the area. The Prototype App successfully targets the Listing of Villages and Informal settlements by being the only all-inclusive, that does not limit listings to Tittle Deed properties and is the only free to list App on the market. The vision is to create a Database containing viable Data of the Informal about sectors of real estate in South Africa and Africa in its entirety. However, in order to better implement and utilize this system, we will continue to test and improve engagement on a small scale in some villages. The results will then be applied to the rest of the Country and eventually, the Continent. Free settlement listing is a door for owners and agents to expand their opportunity to make a sale to a larger audience. With current and future research, we hope to add more specifications and functionalities to enhance the quality of this process. This way we can provide further insights into improving the real estate market in South Africa and help identify some opportunities that can be availed by enhancing this process.

\section{REFERENCES}

[1] Real Estate Building the future of Africa. (2015). Pricewaterhousecoopers.

[2] Sanjib Raj Bhan, M. (2019). Struggling with the Digital Divide: Internet Infrastructure, Policies and Regulations. Economic and Political Weekly, 34(47), 20-26. Retrieved from https://www.jstor.org/stable/4408630

[3] Qing Li, S. (2016). Modeling and simulating a smart information-based real estate online platform. Procedia Computer Science, 111(2017), 339-347. Retrieved Fromhttps://doi.org/10/1016j.procs.2017.06.032

[4] Niina Maarit Novak, A. (2015). Mobility for 'Immovables' - Clouds Supporting the Business with Real Estates. Procedia Computer Science, 63(2015), 120 - 127.

[5] Artur Janowski, M. (2019). Automated Valuation Model based on fuzzy and rough set theory for real estate market with insufficient source data. Land Use Policy, 87(2019).

[6] Worawat Choensawatb, W. (2015). An ensemble learning based model for real estate project classification. International Conference on Applied Human Factors and Ergonomics, 6th.

[7] Data Collection and Mobile Technologies. (2019). doi: 10.13140/RG.2.2.31541.93929 
International Journal of Data Mining \& Knowledge Management Process (IJDKP) Vol.9, No.5, September 2019

[8] Tipaawan Silwattananusarn and KulthidaTuamsuk. Published in (September, 2012). Data Mining and its Applications for Knowledge Management (Literature Review from 2007 to 2012). Retrieved From: aircconline.com/ijdkp/V2N5/2512ijdkp02.pdf

[9] Abdul-Aziz Rashid Al-Azmi. (Published in March, 2013). Data, Text and Web Mining for Business Intelligence. Retrieved From: aircconline.com/ijdkp/V3N2/3213ijdkp01.pdf

[10] Apple.inc. (2019). Apple. Retrieved on 15th September 2019. Web- Retrieved Fromhttps://www.apple.com/ 